\title{
Climate change policy networks: Connecting adaptation and mitigation in multiplex networks in Peru
}

Bruno Locatelli (1,2), Emilia Pramova (2), Monica Di Gregorio (3, 4), Maria Brockhaus (5), Dennis Armas Chávez (2), Ramzi Tubbeh $(6,7)$, Juan Sotés $(6,8)$, Javier Perla $(6)$

1: Cirad, University of Montpellier, France

2: Cifor, Lima, Peru

3: Sustainability Research Institute, University of Leeds, Leeds, United Kingdom

4: Cifor, Bogor, Indonesia

5: International Forest Policy, Department of Forest Sciences, University of Helsinki, Helsinki, Finland

6: Libélula Gestión en Cambio Climático y Comunicación, Lima, Perú

7: currently at Department of Geography, Pennsylvania State University, PA

8: currently at The Atmospheric Fund, Toronto, Canada

This is an Accepted Manuscript of an article published by Taylor \& Francis in Climate Policy on February 25, 2020, available online: https://doi.org/10.1080/14693062.2020.1730153

Full reference: Locatelli B., Pramova E., Di Gregorio M., Brockhaus M., Armas Chávez D., Tubbeh R., Sotés J., Perla J., 2020. Climate change policy networks: Connecting adaptation and mitigation in multiplex networks in Peru. Climate Policy. doi: 10.1080/14693062.2020.1730153

\begin{abstract}
Increasing attention is being given to integrating adaptation and mitigation in climate change policies. Policy network analysis is a way to explore connections between adaptation and mitigation, and the opportunities or barriers to effective integration between these two policy subdomains. This study explores climate governance and policy networks by examining collaboration and information flows in national policy processes in Peru, a country with an active climate change policy domain. In contrast to most climate policy network analyses, this study distinguishes adaptation and mitigation subdomains through a multiplex approach. We used ERGM (Exponential Random Graph Models) to explain the existence of information flows and collaborations among 76 key actors in climate change policy in Peru. We identified actors who could connect adaptation and mitigation subdomains. Results show a concentration of influence in national government actors, particularly in the mitigation subdomain, and the isolation of actor groups that matter for policy implementation, such as the private sector or subnational actors. Results highlight the predominance of mitigation over adaptation and the existence of actors well positioned to broker relationships between the subdomains. The top brokers across subdomains were, however, not only actors with high centrality and brokerage roles in the subdomains, but also several "unusual key players" that were not brokers in any of the two layers separately.
\end{abstract}

\section{Key policy insights}

- National government institutions are central actors in climate change policy networks in Peru, reflecting national ownership of the climate change issue.

- Private sector organizations and subnational actors in Peru are the least involved in information sharing and collaboration on climate change.

- Actors from different levels and sectors are active in both adaptation and mitigation, which is good for climate policy integration.

- Actors with the capacity to bridge the two policy subdomains are not necessarily central to each subdomain but may be actors that close structural holes between subdomains.

Keywords: broker, ERGM, multiplex, network analysis, policy coherence, synergy 


\section{Introduction}

The two main strategies for fighting climate change - adaptation and mitigation - are strongly interlinked. This is particularly true in land-use sectors, because forests and agricultural systems are vulnerable to climate change, help people adapt, and are important sinks and sources of greenhouse gases (Locatelli et al., 2015b). Increasing attention is being given to integrating adaptation and mitigation (A\&M), following evidence that policies and projects with both $A \& M$ objectives can increase synergies and reduce unintended consequences (Kongsager et al., 2016; Locatelli et al., 2015a). The synergetic effects of some land management interventions on A\&M can increase their cost-effectiveness and attractiveness, but synergies are not automatic (Smith et al., 2019).

The Climate Policy Integration (CPI) literature highlights the importance of mainstreaming climate change in other policy domains, to avoid clashes between policy objectives, inefficiencies, or unintended consequences and simply to ensure the effectiveness of climate policy (Adelle and Russel, 2013; den Hertog and Stross, 2013; Persson, 2013; Russel et al., 2018; Scobie, 2016). CPI encompasses policy integration and policy coherence. While these terms have been variously understood (Adelle and Russel, 2013), we follow Nilsson et al. (2012) in considering that policy integration refers to integration of administrative and organizational governance arrangements and policy making processes, while policy coherence refers to policy outputs and outcomes, or the consistency of multiple policy objectives and associated implementation. However, the CPI literature mostly discusses external policy coherence, or the consistency of climate change and non-climate policy objectives, which is also often referred to as mainstreaming climate change (Adelle and Russel, 2013; Nilsson et al., 2012).

In this paper, we investigate climate policy integration that facilitates internal climate policy coherence, or the integration of climate change A\&M policy processes, independently from the sectoral domain (Di Gregorio et al., 2017). Internal policy coherence is necessary to identify mutually beneficial practices (synergies and co-benefits) and reduce negative interactions (trade-offs) between $A \& M$ responses. These synergies can be facilitated by the integration of both $A \& M$ objectives in intervention design and by a better coordination between policy actors interested in either adaptation or mitigation. Integrating A\&M policy processes can lead to internal climate policy coherence in climate policy domains, with analyses of the positive and negative effects of adaptation on mitigation (and vice-versa) and the development of programmes with joint objectives where it makes sense (Locatelli et al., 2011; Pham et al., 2014; Swart and Raes, 2007). The A\&M integration can also lead to external policy coherence with the mainstreaming of integrated $A \& M$ objectives into sectoral policies (Di Gregorio et al., 2017).

An important challenge in climate change governance in general, and in integrating $A \& M$ in particular, is the institutional complexity that emerges when various actors are involved (Adelle and Russel, 2013; Schmidt and Fleig, 2018; Shrestha and Dhakal, 2019). Even within the separate policy subdomains of $A \& M$, institutional barriers and lack of coordination are major obstacles for successful implementation of programs and strategies (Brockhaus and Di Gregorio, 2014; Calliari et al., 2019; Oberlack, 2017; Stringer et al., 2012). Another important barrier to the integration of A\&M relates to the lack of information on how the two policy subdomains are linked (Locatelli et al., 2015b; Shrestha and Dhakal, 2019) and how to improve information exchange and collaboration between them (Di Gregorio et al., 2017; Shrestha and Dhakal, 2019).

Policy network analysis can help explore the opportunities and barriers to effective integration between A\&M subdomains (Di Gregorio et al., 2019; Gallemore et al., 2015). Policy networks have become an important topic in environmental governance (Bulkeley, 2005; Carlsson and Sandström, 2008; Cashore and Vertinsky, 2000; Weible and Sabatier, 2005) and have also been explored in climate change policies (Di Gregorio et al., 2019; Ingold, 2011; Yun et al., 2014). For example, policy network analyses have been used to investigate policy processes related to Reducing Emissions from 
Deforestation and forest Degradation (REDD+) (Brockhaus et al., 2014) and adaptation governance (Calliari et al., 2019; Ingold, 2017; McAllister et al., 2014; Vignola et al., 2013). Few policy network studies have looked at the links between the two climate change policy subdomains of A\&M (but see Di Gregorio et al., 2019).

Improved integration of policy processes through networked relationships between policy actors is not the only way to bring about policy integration. Many policy scholars have shown that there are many other dimensions to integration and networked governance. For instance, Tosun and Lang (2017) distinguished two approaches to policy integration: a substantive approach that builds interdependencies and coordination between policy domains (where networked relationships between policy actors play a role) and a procedural approach that develops specific policy instruments for integration. Russel et al. (2018) analysed how policy appraisal (defined as ex-ante evaluation of policy consequences) can help policy integration.

This study explores climate governance and policy networks by examining collaboration and information flows in national policy processes in Peru, a country with an active climate change policy domain. The study differs from most climate policy network analyses by distinguishing A\&M subdomains in order to assess the level of internal climate policy integration in the land-use sector. By examining the climate change policy network of Peru through a multiplex network approach, the study discerns actor properties across subdomains that cannot be identified by looking at A\&M separately. The study aims to answer the following research questions: What is the structure of the Peruvian climate change policy network and what opportunities and challenges does it present for climate policy integration? How do networks differ in the A\&M subdomains and what is the role of brokers in supporting the integration of the two subdomains? Answers to these questions will offer new insights and guidance for efforts to enable synergies across A\&M.

\section{Theoretical background and propositions}

Policy networks are comprised of formal and informal linkages between policy actors engaged in public policy making and implementation (Knoke and Yang, 2008; Marsh and Rhodes, 1992). They are problem-specific and organize a given policy area by different forms of collective action and resource exchange (Carlsson, 2000; Carlsson and Sandström, 2008). Policy networks reflect existing power relations, alliances, conflicts and constraints of their broader political context (Marsh and Smith, 2000).

Policy network analysis investigates interactions among policy actors in a policy domain. It can identify the organizations and policy coalitions that play a key role in formulating and implementing climate policies and those that are instead peripheral or isolated. Furthermore, network structure can explain the outcomes of a whole domain or individual organizations in the network (Borgatti et al., 2009; Burt, 2004; Gargiulo and Benassi, 2000). This information is valuable for designing strategies to enhance institutional linkages (Calliari et al., 2019).

The following paragraphs describe the propositions that guided our analysis in Peru, based on previous research on policy network analysis, on climate change or more broadly. The first ones refer to the central actors. Climate change policy networks bring together societal actors beyond formal state hierarchies, and even beyond national borders, such as NGOs, businesses and international organizations, who all try to influence policy processes and outcomes (Bodin and Prell, 2011; Broadbent and Vaughter, 2014). Political disputes and competing interests often override solutionoriented, rational, science-based processes in the formulation of policies. This is even more pronounced in the complex environmental policy arenas characterized by multi-level, multi-sector and multi-actor networks (Brockhaus et al., 2014).

Due to their organizational type, governmental actors are, by definition, influential, as they hold formal decision-making power (Leifeld and Schneider, 2012) and are central to multiple climate policy networks (Brockhaus and Di Gregorio, 2014; Calliari et al., 2019; Di Gregorio et al., 2019). 
Ministries, and especially the ones related to environment and finance, are the key institutions influencing climate policies, including the distribution of finance between A\&M (Pickering et al., 2015). For this reason, the following proposition is formulated: (P1) National government actors are the most central policy actors in the Peruvian climate policy network.

International actors are also highly influential in national climate change policy processes and networks in the Global South, where climate change action relies largely on multilateral and bilateral funding (Brockhaus and Di Gregorio, 2014; Pickering et al., 2015). Furthermore, international organizations (including intergovernmental organizations (IGOs), development agencies of foreign governments and international NGOs) deliver specialized climate change expertise (Hall, 2017). For these reasons, we expect that: (P2) International organizations are central policy actors in the climate policy network of Peru.

Climate change mitigation has attracted more international attention than adaptation, particularly in the early international climate change agreements, such as the Kyoto Protocol (Pielke Jr et al., 2007). Adaptation implementation has also been slow to rise and has faced ambiguities on what constitutes adaptation (Hall, 2017). Even though the situation has changed, mitigation is still attracting the majority of global climate finance (Locatelli et al., 2016). We suggest that this historical dominance of mitigation over adaptation at the international level is still visible in national policy domains, particularly in countries with an important mitigation potential, for example large areas of tropical forests at risk of deforestation, such as in Peru: (P3) There is more information sharing and collaboration on mitigation than adaptation in the climate policy network in Peru.

Adaptation has a more local nature than mitigation, which has global benefits (Locatelli, 2011). Consequently, policy actors that are active at subnational level, such as local government actors and development NGOs, are expected to be more engaged in the adaptation subdomain (Di Gregorio et al., 2019). The predominance of mitigation in international funding may push international actors to be more active in the mitigation policy discussions within a country. For these reasons, we devise the following proposition: (P4) International organizations are more engaged in mitigation, while subnational government actors and NGOs are more engaged in adaptation within the climate policy network in Peru.

In terms of sectoral focus, forests and agriculture have been at the center of climate change policies. Forests have been high on the international climate mitigation agenda since negotiations started on policy instruments such as REDD+ and the Clean Development Mechanism, while the agriculture sector has been more concerned with adaptation due to its perceived high vulnerability to climate variations (UNFCCC, 2017). We thus expect that: (P5) Actors mostly focusing on forest activities are more engaged in mitigation, while actors mostly focusing on agriculture are more engaged in adaptation within the climate policy network in Peru.

Perceived influence, also known as reputational power, drives power relations and reinforces concentration of power (Knoke et al., 1996; Kriesi and Jegen, 2001). For example, actors are more likely to exchange information with actors they perceive to be particularly influential (Leifeld and Schneider, 2012). Perceived influence has been found to be important for collaboration and alliance building, as influential actors are preferred as partners (Berardo and Scholz, 2010; Weible and Sabatier, 2005). However, given the differences between A\&M, we devise the following proposition: (P6) High reputational power in one policy subdomain of the climate policy network in Peru (either adaptation or mitigation) is accompanied by high information sharing and collaboration in the same subdomain, but not in the other.

Policy network analyses have often shown that people and organizations tend to connect to others who are similar (McPherson et al., 2001). Homophily posits that actors connect based on similarities in order to reduce collaboration risks, as dissimilarities can lead to conflicting interests and increased transaction costs (Lee et al., 2012; Lubell, 2007). This suggests the following proposition: (P7) Policy 


\section{actors of the same type are more likely to share information and collaborate with each other within the climate policy network in Peru.}

Finally, given the historical separation between the two climate subdomains in policy development, a better integration of the two may be facilitated by cross-domain brokers. Policy network analysis can help identify brokers, i.e. key actors that mediate linkages among different actors within or between policy subdomains (Wasserman and Faust, 1994). Theoretical works have formalized the analysis of brokers across layers in multilayered or multiplex networks (Kumar et al., 2019; Solé-Ribalta et al., 2014) and shown that neglecting the multilayer structure of a network leads to misidentifying brokers (De Domenico et al., 2015; Ghariblou et al., 2017). For our analysis, this means that: (P8) Actors who are important brokers across domains are not necessarily important brokers in either subdomain of the climate policy network in Peru.

\section{Methods}

\section{Case study}

Forests, agriculture and other land-use sectors are high in the A\&M policy agendas in Peru. Since land-use changes are responsible for almost half of Peruvian emissions, REDD+ represents mitigation opportunities (Menton et al., 2014). Peru is also highly vulnerable to the impacts of climate change. Adaptation policies have been developed, including through ecosystem-based adaptation, an important adaptation strategy for restoring, conserving and enhancing ecosystem services to reduce people's vulnerability (Chazarin et al., 2014; Oliver-Smith, 2014). Several Peruvian policies aim to address climate change by integrating A\&M goals, such as the Action Plan for Climate Change Adaptation and Mitigation, the National Environment Policy and the National Forestry and Wildlife Policy. Climate change objectives are found in almost all policies from the relevant sectors (land use, forestry, agriculture, disaster risk reduction and sustainable development) (Pramova et al., 2015).

Civil society is active in the climate change policy domain in Peru, and there is a strong presence of international organizations and donors (Piu and Menton, 2014). The Ministry of Environment has direct jurisdiction over all activities related to climate change, which it oversees through General Directions, the National Service of Natural Protected Areas and the National Forest Conservation Programme for the Mitigation of Climate Change. However, many other sectors and institutions, such as the Ministry of Agriculture, the different regional governments, national and international NGOs and IGOs are also involved in the climate change arena (Menton et al., 2014).

\section{Research design and data collection}

The terminology used in this study includes policy actors or 'actors' (organizations that are part of the climate policy domain), 'relation' or 'tie' (information sharing and collaboration), and 'policy subdomain' (set of actors and their relation to either adaptation or mitigation). A 'layer' refers to a set of relations within a policy subdomain, of a specific type (e.g. the layer of collaboration on adaptation) or any type (e.g. the layer of adaptation).

We began by defining the policy network boundaries and mapping all relevant actors, i.e. organizations that had been involved with or influenced national-level climate change policies and land management (Laumann and Knoke, 1987). For this purpose, we convened a workshop in late 2014 with key stakeholders from different organizations (government, civil society, academia and international, intergovernmental and private sector organizations). Workshop participants identified 320 policy actors, scored their relevance (i.e. their involvement and influence in the policy cycle) and finally selected 100 actors to be interviewed. In mid 2015, we interviewed representatives of 76 of these organizations. We classified the 76 actors into three different levels of governance (where they originated: international, national and subnational), and six organizational types. These were combined in ten non-empty level-type combinations, called groups (Table 1). 
Table 1: The six types, three levels, and ten groups (i.e., level-type combinations) of policy actors interviewed

\begin{tabular}{|c|c|c|c|c|c|}
\hline & & Levels & & & \\
\hline & & $\begin{array}{l}\text { INT: } \\
\text { International }\end{array}$ & $\begin{array}{l}\text { NAT: } \\
\text { National }\end{array}$ & $\begin{array}{l}\text { SUB: } \\
\text { Subnational }\end{array}$ & Total \\
\hline Types & $\begin{array}{l}\text { FOR: Foreign agencies and representatives of foreign } \\
\text { governments, such as governmental agencies for } \\
\text { international cooperation }\end{array}$ & $\begin{array}{l}6 \\
(I-F O R)\end{array}$ & - & - & 6 \\
\hline & $\begin{array}{l}\text { GOV: Governments, state agencies and expressly } \\
\text { political organizations (bureaus, departments, } \\
\text { specialized and technical agencies) }\end{array}$ & - & $\begin{array}{l}15 \\
(\mathrm{~N}-\mathrm{GOV})\end{array}$ & $\begin{array}{l}11 \\
\text { (S-GOV) }\end{array}$ & 26 \\
\hline & $\begin{array}{l}\text { IGO: Intergovernmental organizations (e.g. World } \\
\text { Bank, FAO, UN-REDD...) }\end{array}$ & $\begin{array}{l}7 \\
(I-I G O)\end{array}$ & - & - & 7 \\
\hline & $\begin{array}{l}\text { NGO: Non-governmental organizations, charities, } \\
\text { foundations, other non-for-profit, grass-root } \\
\text { organizations, networks of NGOs }\end{array}$ & $\begin{array}{l}5 \\
(I-N G O)\end{array}$ & $\begin{array}{l}9 \\
\text { (N-NGO) }\end{array}$ & $\begin{array}{l}5 \\
(\mathrm{~S}-\mathrm{NGO})\end{array}$ & 19 \\
\hline & $\begin{array}{l}\text { PRI: Private sector (business associations, trade } \\
\text { associations, insurance, banks, investors, single } \\
\text { businesses and consultants) }\end{array}$ & - & $\begin{array}{l}7 \\
\text { (N-PRI) }\end{array}$ & - & 7 \\
\hline & $\begin{array}{l}\text { RES: Research institutes, think tanks, academic } \\
\text { institutions }\end{array}$ & $\begin{array}{l}5 \\
(I-R E S)\end{array}$ & $\begin{array}{l}6 \\
\text { (N-RES) }\end{array}$ & - & 11 \\
\hline & Total & 23 & 37 & 16 & 76 \\
\hline
\end{tabular}

The survey included questions about four different types of relations. We asked the interviewees to mark with which of the other actors they had regularly exchanged information on adaptation (iA layer) or mitigation (iM), and collaborated on adaptation (cA) or mitigation (cM) over the last 12 months, a period that included the $20^{\text {th }}$ Conference of the Parties (COP20) to the United Nations Framework Convention on Climate Change (UNFCCC) in Lima (December 2014). Information sharing was defined as regular exchanges of any kind of information related to the policy subdomains and included sending regular emails, discussing face to face, or disseminating material. Information sharing can underlie activities like lobbying but exchanges of information might also occur between rival policy actors (Granovetter, 1977; Leifeld and Schneider, 2012). Collaboration was defined as working together towards a common goal. We also asked actors to mark the organizations that they considered particularly influential in each policy subdomain, which identified "influence attribution" ties between actors (Fischer and Sciarini, 2015) and measured the reputational power of actors (Knoke, 1993; Leifeld and Schneider, 2012).

\section{Data analysis}

The primary data was composed of four 76 by 76 binary adjacency matrices representing directed ties, in addition to actor attributes (sector, level, type and group). The adjacency matrices were used to create four unweighted and directed network layers representing different relations (information and collaboration) in the two climate change policy subdomains (see layers in supplemental online material SOM1).

Our analysis included two major steps (Fig. 1). The first step considered the four layers separately (iA, $\mathrm{iM}, \mathrm{CA}$ and $\mathrm{cM}$ ). To explore propositions 1 to 3, we calculated descriptors of layers and actors (e.g. their indegree centrality defined as the number of incoming ties). To compare actor centrality by groups, we calculated the average of the actors with the three largest indegree centrality in the group because the influence of a group is largely dictated by its most influential actors (Brockhaus and Di Gregorio, 2014). We then modelled the presence of ties based on several predictors using exponential random graph models (ERGMs) (see next section). The second step adopted a multiplex perspective (described in more detail later), in which we analysed the ties within each subdomain (intra-layer) and across them (inter-layer) (Fig. 1, right). 
1 Explaining ties in relation layers

with endogenous effects (i.e., structural)

and exogenous effects (described below)

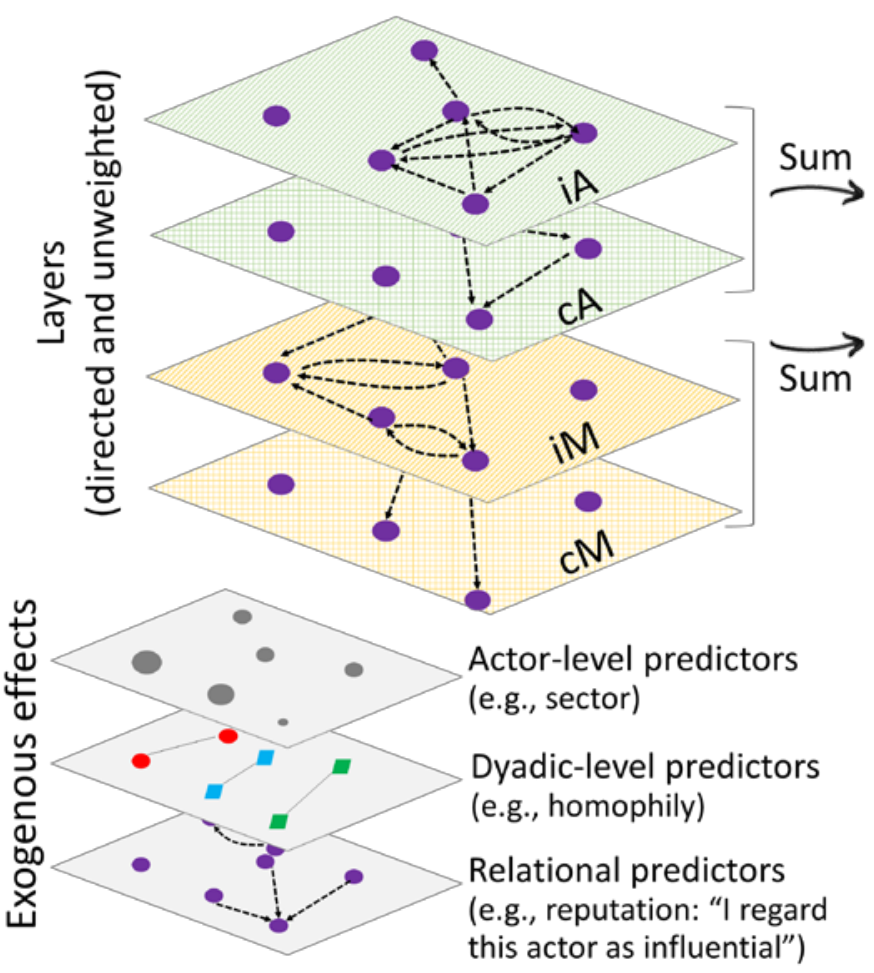

Analyzing actor centrality in A and $\mathrm{M}$ sub-domain layers and between them

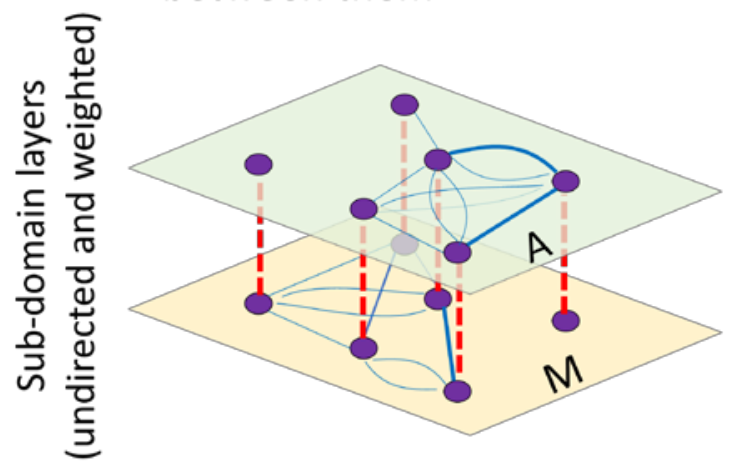

Directed unweighted tie

Undirected weighted tie

Self-coupling tie

i Information exchange

("I exchange information with this actor")

c Collaboration

("I collaborate with this actor")

A Adaptation subdomain

$M$ Mitigation subdomain

Figure 1. Overview of the data and the two major steps of the analysis

\section{ERGMs to explain ties in relations layers}

To explore propositions 4 to 7, we analysed how actor groups (P4), sectors (P5), reputational power (P6) or type similarity (P7) influenced the existence of a tie between two actors. We distinguished between information sharing and collaboration, because they refer to different types of relations, not just different intensities. Information sharing includes any communication between actors sharing similar values or between political opponents (Granovetter, 1977; Leifeld and Schneider, 2012), while the collaboration ties are specific to coalition work and much more dependent on trust (Carpenter et al., 2004; Ingold, 2011). Previous research showed that these two types of ties lead to different network configurations and different central actors (Gebara et al., 2014; Lee, 2019). As our results show, a separate analysis of information sharing and collaboration networks can highlight different network structures and key actors (e.g., opinion leaders or action catalysts).

We used ERGMs, which are models to explain the existence of ties in the networks. The existence of ties could have been explained by simple statistical models, for example log-linear models that explain the existence of a tie between two actors with the characteristics of the actors. However, such models assume that observations are independent, which is not the case of the ties within a network. For example, the existence of a tie from actor $A$ to actor $B$ will influence the existence of a tie from $B$ to $A$ because of reciprocity, which is a common feature of social relationships. Similarly, because of transitivity, another common feature of social relationships, the existence of a tie from $A$ to $B$ will depend on whether $A$ and $B$ have a tie to a third actor (Lusher and Robins 2012). 
Because the existence of a tie depends on the rest of the network, we used ERGMs, which were developed specifically for network analysis to account for the effects of network structure on tie formation (Cranmer and Desmarais, 2011).

Ties in an ERGM can be explained by several types of effects, including structural, actor level, dyadic level and relational (Robins and Lusher, 2013) (Fig. 1, left). First, structural effects (also known as endogenous effects) capture how ties organize themselves into patterns under the influence of network structure (i.e. how the existence of certain ties affects the existence of others). Examples of such effects include reciprocity (a tie from an actor to another is more likely to exist if the reciprocal tie exists) and transitivity (two actors are more likely to create a tie if they are both tied to a third actor) (Koskinen and Daraganova, 2013; Leifeld and Schneider, 2012). If structural effects are not considered, we may estimate the importance of other effects in tie formation incorrectly (Lusher and Robins, 2013) (see example in SOM4). Second, actor-level effects describe how tie probability depends on the characteristics of the actors on either or both sides of a tie. Third, dyadic-level effects test the effect of the attributes of a pair of actors on the tie between them, for example to assess homophily. Fourth, the relational predictors (also known as covariate networks) capture how a relation affects another relation. In our case, we used a relational predictor to assess the role of reputational power in explaining ties: while reputational power is often considered as a characteristic of policy actors, it can also be understood as a relation (i.e. an actor considers another actors as powerful or influential) (Fischer and Sciarini, 2015; Heaney, 2014; Leifeld and Schneider, 2012).

We developed four ERGMs with the same effects to explain ties in the four layers of information sharing and collaboration (Table 2). We fitted the ERGMs with a Markov Chain Monte Carlo simulation and applied diagnostic tools and goodness-of-fit analysis to check whether the models were good representations of the observed network (Butts et al., 2015) (details in SOM5). All calculations were made in R (R Core Team, 2018) with the ergm and sna packages (Handcock et al., 2016).

Table 2. Effects considered in the ERGMs (exponential random graph models)

\begin{tabular}{|c|c|c|c|}
\hline Type of effect & Effect & Interpretation & $R$ code \\
\hline Baseline & Edge & $\begin{array}{l}\text { Baseline effect on tie formation } \\
\text { (creating network layers with the right } \\
\text { number of edges) }\end{array}$ & edges \\
\hline \multirow[t]{2}{*}{ Structural } & Reciprocity & $\begin{array}{l}\text { Reciprocated ties are likely (if the effect } \\
\text { estimate is positive) }\end{array}$ & mutual \\
\hline & Transitivity & $\begin{array}{l}\text { Actors with shared partners are more } \\
\text { likely to be tied (if the effect estimate is } \\
\text { positive) }\end{array}$ & gwesp(0.5, fixed=T) \\
\hline \multirow[t]{2}{*}{$\begin{array}{l}\text { Actor level } \\
\text { (receiver side of } \\
\text { the tie) }\end{array}$} & Group & $\begin{array}{l}\text { Actors from a given level and type are } \\
\text { more or less likely to receive incoming } \\
\text { ties }\end{array}$ & nodefactor(“Group”) \\
\hline & Sector & $\begin{array}{l}\text { Actors with a high involvement in a } \\
\text { given sector are more or less likely to } \\
\text { receive incoming ties }\end{array}$ & $\begin{array}{l}\text { nodecov("Degree of } \\
\text { involvement in one sector") }\end{array}$ \\
\hline Dyadic level & Homophily & $\begin{array}{l}\text { A pair of actors of the same type are } \\
\text { more or less likely to be tied }\end{array}$ & $\begin{array}{l}\text { nodematch("Level" or } \\
\text { "Type", diff=T) }\end{array}$ \\
\hline Relational & Reputation & $\begin{array}{l}\text { An actor is more or less likely to have } \\
\text { ties with actors that it considers } \\
\text { influential }\end{array}$ & edgecov(Reputation) \\
\hline
\end{tabular}




\section{Multiplex perspective: Brokerage between A\&M subdomains}

To identify the brokers within and across the two policy subdomains and explore proposition 8 , we adopted a multiplex network perspective, which considers that actors are connected through more than one type of relation. In a multiplex social network, people are connected by different ties (e.g., kinship or friendship), which are represented in different layers forming a multiplex network (Kivelä et al., 2014). The analysis of multiplex networks can highlight processes and structures that cannot be explored with separate single networks (Heaney, 2014).

As we were interested in understanding the connections between A\&M subdomains, we built a multiplex network with two A\&M layers (Fig. 1, right). Each layer was built from the information sharing and collaboration layers, transformed into undirected and weighted layers (with weight of 2 for ties reported by both actors in a dyad and 1 for ties reported by only one actor) and summed (resulting in subdomain layers with edge weights of 1 to 4). We summed information sharing and collaboration layers because, in this step, we were interested in how policy actors interacted in A\&M, regardless of the type of ties. However, to recognize that reciprocal information and collaboration ties lead to stronger ties in the A\&M layers, we used weighted layers to describe A\&M ties.

The subdomain layers formed a multiplex or multilayer network (Dickison et al., 2016), in which the same actors exist in the two layers and interact differently about A\&M. Multiplex networks allow the identification of actor and network properties that cannot be explained by looking at individual network layers alone (Heaney, 2014). Within the multiplex network, we investigated self-coupling ties (vertical red lines in Fig. 1, right), which link an actor in a subdomain with the same actor in the other (Zeng and Battiston, 2016).

We identified intra-layer as well as inter-layer brokers. Intra-layer brokerage was measured with actor betweenness and inter-layer brokerage with the betweenness of the self-coupling tie of an actor (Battiston et al., 2018; Wasserman and Faust, 1994). Tie weights were used to calculate weighted betweenness (inverse weights were interpreted as distances in the network). We then analysed how brokerage across layers related to brokerage within layers. We also identified the top $20 \%$ of brokers in the multiplex network within or across layers. All calculations were made in $\mathrm{R}(\mathrm{R}$ Core Team, 2018) with the igraph package (Csardi, 2018). 


\section{Results}

\section{The climate change policy network}

In the two information layers of the climate change policy network in Peru, information could potentially flow across the whole network of actors, as there was only one component, while the collaboration layer on mitigation showed two components, and thus non-connected groups of actors (Table 3). Layers showed slightly higher densities for mitigation than adaptation, especially for information exchange. This indicates that the mitigation subdomain was slightly more active than the adaptation subdomain. Densities were generally higher in information sharing than in collaboration, but this was expected, as collaboration is a more resource-intensive relation. We found layers to be highly reciprocal with reciprocity values of $0.27-0.33$ (expected values with the same numbers of ties randomly distributed are $0.05-0.10$ ).

Table 3. Basic descriptors of the relation layers of information and collaboration ties on adaptation (A) and mitigation (M)

\begin{tabular}{lllll}
\hline & Information & \multicolumn{2}{c}{ Collaboration } \\
\hline & $\mathrm{A}$ & $\mathrm{M}$ & $\mathrm{A}$ & $\mathrm{M}$ \\
\hline $\begin{array}{l}\text { Number of weak components (i.e. groups of actors in which every actor is } \\
\text { reachable from every other actor through one or several ties; "weak" }\end{array}$ & 1 & 1 & 1 & 2 \\
because tie direction is not considered) & & & & \\
\hline $\begin{array}{l}\text { Density (proportion of observed ties in a network to the maximum number } \\
\text { of possible ties) }\end{array}$ & 0.15 & 0.18 & 0.09 & 0.10 \\
\hline Reciprocity (proportion of mutual connections in the directed graphs) & 0.27 & 0.33 & 0.30 & 0.31 \\
\hline
\end{tabular}

All layers were positively correlated to the others (details in SOM2), with high correlation coefficients (0.53-0.55) between relations of a similar nature ( $\mathrm{iA}$ and $\mathrm{iM}$ or $\mathrm{CA}$ and $\mathrm{CM}$ ) and even higher correlation coefficients (0.59-0.61) between ties in each policy subdomain ( $\mathrm{CA}$ and $\mathrm{iA}$ or $\mathrm{CM}$ and $\mathrm{iM}$ ).

Most central actors were from the national government in all layers, followed by international actors: foreign agencies (particularly in adaptation) and IGOs (in both A\&M) (Fig. 2). International NGOs were less central than the other international actors, except in the iA layer. In the iM layer, central actors included national NGOs, active in bringing issues of justice and rights to REDD+ discussions. Private sector actors were the least connected and subnational NGOs the second least in most layers. NGOs, both international and domestic ones, were more central in information networks than in collaboration networks, with the exception of subnational NGOs. Subnational governments were not central in information sharing but ranked higher in collaboration. Research actors had medium centrality, with international research being more central in mitigation and national research in adaptation. 

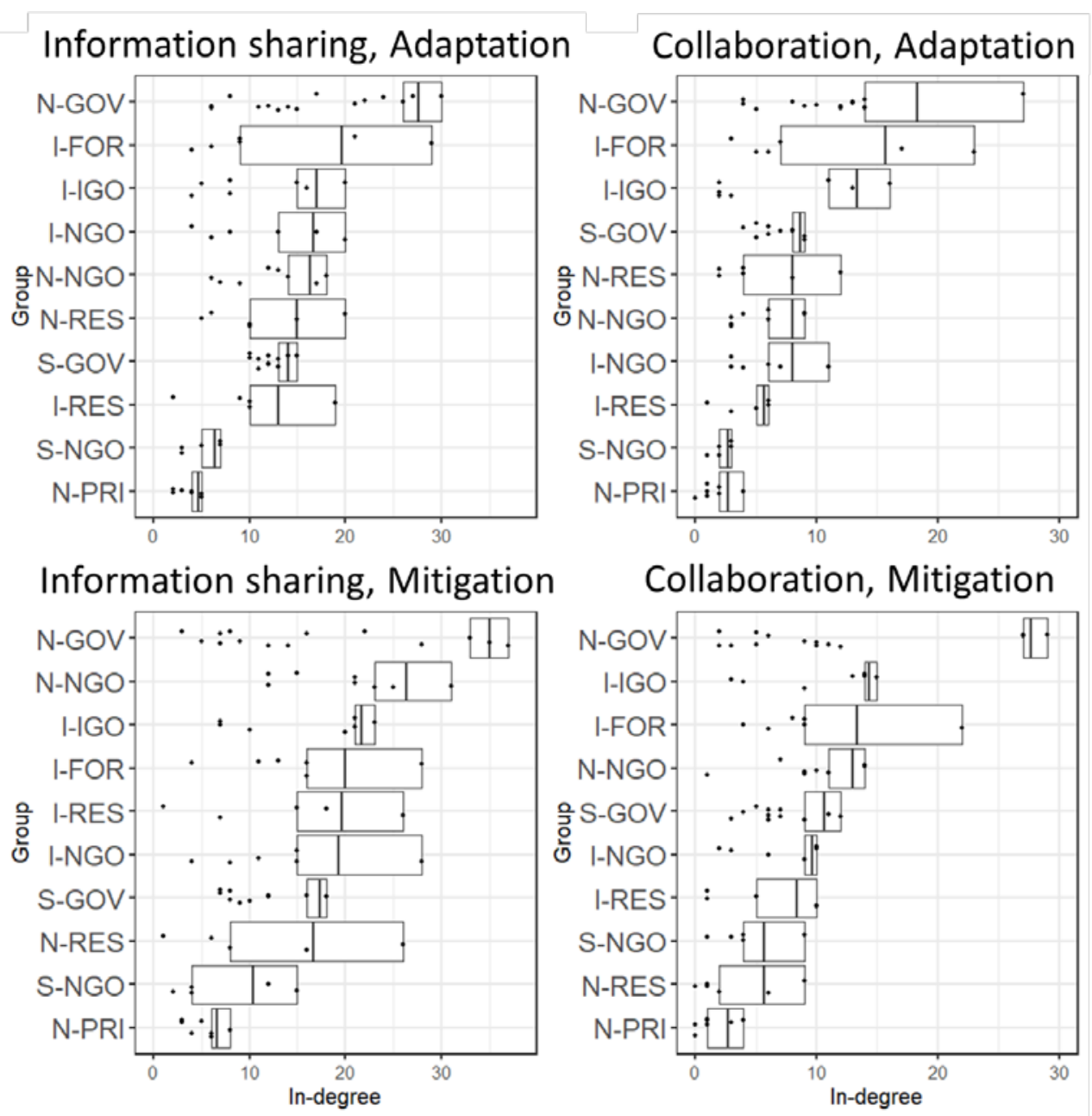

Figure 2. Indegree by group of actors in the four relation layers. Groups are ordered differently in each plot depending on the average indegrees (shown by vertical lines) of top three actors in each group (show in boxes)

\section{ERGM results}

Structural effects were significant predictors of tie occurrence in all four layers (Fig. 3, row 1). Reciprocity had a strong effect in collaboration, which is unsurprising as both actors involved in a collaboration are likely to report it. Transitivity had a strong effect in information sharing, which means that actors look for contacts of their contacts to establish new information ties and, to a lesser extent, new collaborations, indicating that trust expands interactions in the network.

The most influential actors were government agencies from all levels, either with legal authority (national and subnational governments) or international funding capacity (foreign agencies) (Fig. 3, row 2). Actor group had a stronger effect on the mitigation ties than on the adaptation ties meaning that the attractiveness of some groups is more evident in mitigation exchanges. National government agencies were more likely to be sought as collaboration partners by other actors on mitigation compared to any other group but subnational governments and foreign agencies. These two groups were as popular as the national government group in all layers, except in collaboration on adaptation, where foreign agencies had more ties.

Both national and international research actors were as central as national government actors in information sharing, but were significantly less important partners in collaboration. This was to be 
expected as research institutes primarily disseminate scientific information. In all layers, the subnational NGOs and the private sector were less sought after as information and collaboration partners than the national government. Sector had a limited effect on tie formation (Fig. 3, row 2): only involvement in the forestry sector increased the probability of forming information ties on mitigation, which is not surprising as mitigation policies focus on the forestry sector in Peru.

Homophily was common (Fig. 3, row 4): in almost all layers, NGOs, the private sector and research actors were more likely to interact with actors of the same type. This might indicate a coordination of lobbying activities among interest groups (such as NGOs and private sector) and research activities among research institutions. The homophily in information sharing among research institutions raises concern about their role in disseminating research results to society. IGOs showed homophily only in the layer of information sharing on mitigation, which could indicate a difficulty in effective information exchange with national actors within the mitigation subdomain. We also observed strong heterophily with foreign government agencies, which were more likely to be tied to organizations outside of their group than inside, probably because their mission is to support other types of actors and they do it successfully.

Finally, we observed strong reputational power effects (Fig. 3, row 5): an actor was more likely to share information and collaborate on mitigation with an actor it considered influential in mitigation. We observed the same effect, but weaker, in the adaptation subdomain. This is not surprising, as actors will establish more ties with an actor of high perceived influence. Interestingly, high reputational power in mitigation increased tie probability slightly in adaptation, whereas high reputational power in adaptation decreased tie probability slightly in mitigation, which may underline the dominance of mitigation actors in the climate change policy domain. It might also reflect that mitigation experts were perceived as experts in climate change in general, whereas adaptation experts were perceived as more specialized.

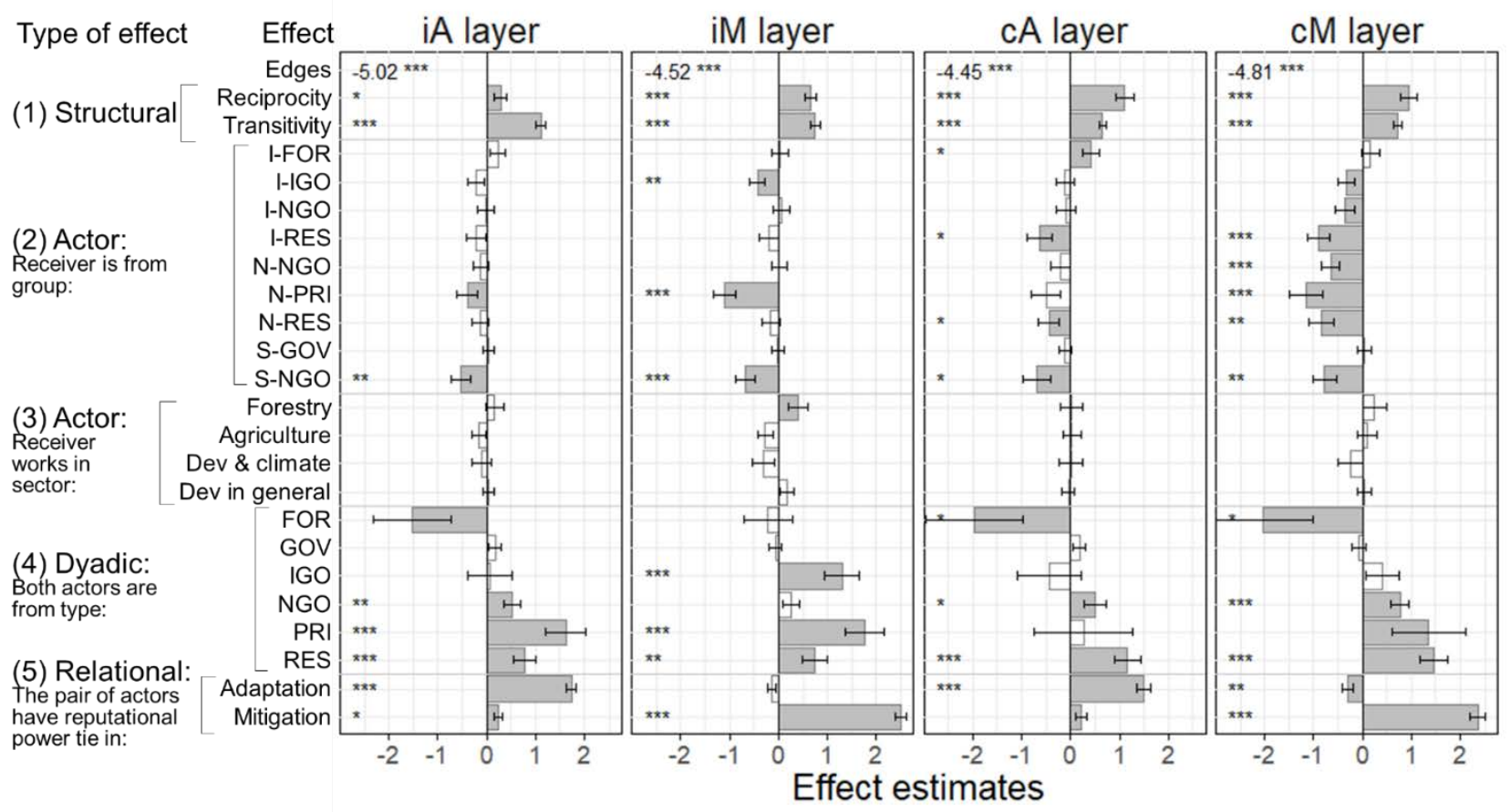

Figure 3. Visualization of the results of the ERGMs for the four layers. Effect estimates are represented by bars (grey if the effect is significant at $p<0.1$ ) and standard errors with whiskers. As the estimate of the intercept is interpreted differently from the others, its value is written in numeric form. The $p$-values are represented at the left of the bars as significance codes ( $* * *$ $p<0.001, * * p<0.01, * p<0.05)$ 


\section{Brokers in and between the subdomains}

Some actors were major cross-subdomain brokers, facilitating interactions between the A\&M subdomains, for example actors \#5 (a division for climate change at the environment ministry) and \#64 (a UN program) (Fig. 4). These two example actors had mandates that spanned both A\&M; they were also important brokers within both individual subdomains, allowing them to connect many pairs of actors.

Adaptation Mitigation

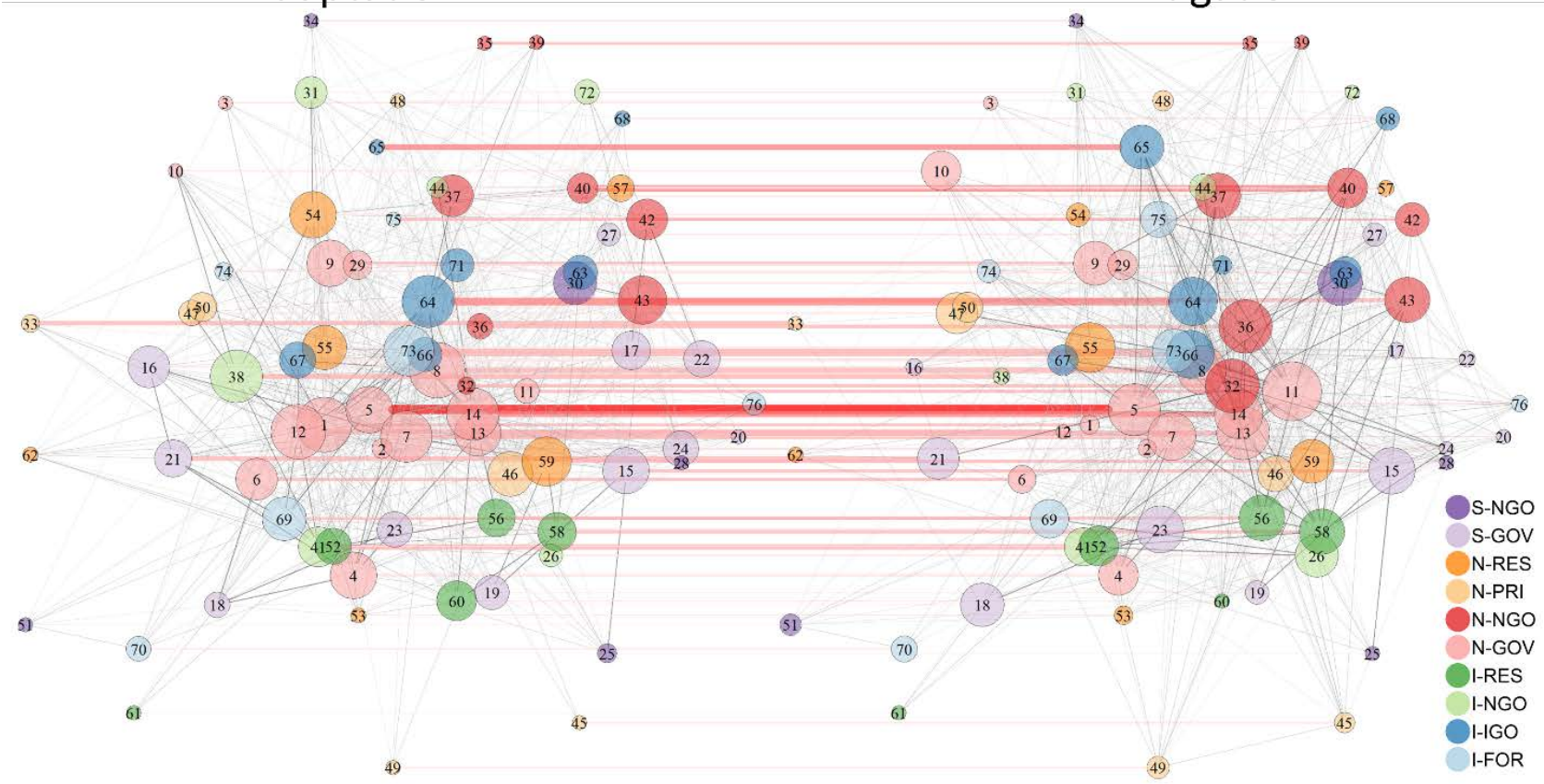

Figure 4. Representation of the multiplex network, with the adaptation layer to the left, the mitigation layer to the right, and self-coupling ties in between (wider and darker for large edge betweenness). The diameters of the actors (circles) are proportional to their betweenness in the layer where they are represented

More generally, brokerage across subdomains correlated positively and significantly $(p<0.01)$ to the brokerage role in either subdomain. Important brokers in mitigation were slightly more likely to be prominent cross-subdomain brokers than important brokers in adaptation (Table 4); again, likely indicating the dominance of mitigation actors in climate change policy domain.

Table 4. Results of a linear model explaining the rank of the brokerage role across subdomains as function of the ranks of the brokerage roles within subdomains

\begin{tabular}{llll}
\hline & Estimate & Standard Error & p-value \\
\hline Intercept & 10.7 & 4.61 & 0.02 \\
\hline Rank of the brokerage role in adaptation & 0.33 & 0.10 & 0.002 \\
\hline Rank of the brokerage role in mitigation & 0.39 & 0.10 & 0.0003 \\
\hline
\end{tabular}

Not all prominent cross-subdomain brokers were important brokers in both subdomains. Four actors were important cross-subdomain brokers despite being important brokers in only one subdomain: one in mitigation (\#66, an international development bank) and three in adaptation (\#12 a national 
government agency specialized in weather and hydrology, \#38 an international NGO and \#43 a national NGO) (Fig. 5).

All six actors that were top brokers in both subdomains (five governmental organizations and one international organization) were also top brokers across subdomains (Fig. 5, top right corner). Surprisingly, some well-known actors appeared as top brokers in one subdomain but not across them. For example, a foreign agency with a large portfolio of climate change activities in the country (and among the $10 \%$ of actors with the highest indegrees in all relation layers) did not appear as a top broker for mitigation or across subdomains, probably because of its redundancy in connecting actors that would be already connected without this actor (see discussion).

Five actors were top brokers across subdomains without being top brokers in any subdomain (Fig. 5, grey circle in bottom left corner) and included a regional government (\#21), a national association of agricultural producers (\#33), a national NGO (\#40), an international NGO (\#41) and an international organization (\#65). These actors had a surprising brokerage role probably because they filled structural holes in the network (see discussion).

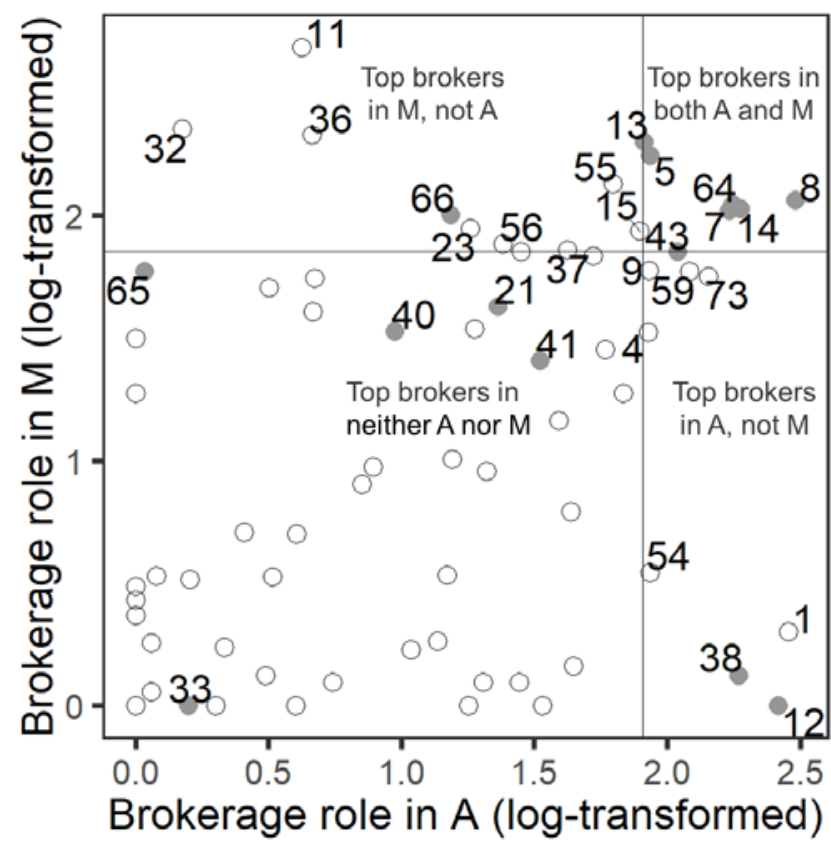

Top broker

across

A and $M$

- Yes

No

Actor

labels:

Only for top

brokers

within or

across

subdomains

Figure 5. Representations of the policy actors (circles) according to their broker role in adaptation ( $x$-axis) and in mitigation ( $y$-axis). Circles at the right/top of the vertical/horizontal line are the $20 \%$ top adaptation/mitigation brokers. Grey circles represent the top $20 \%$ brokers across subdomains. Labels are omitted for actors that are not top brokers within or across subdomains. 


\section{Discussion}

Our analysis of the structure of the climate policy network in Peru can inform about the potential for multi-actor coordination and cooperation (Calliari et al., 2019) and about power configuration within polycentric climate governance (Börzel, 1998; Ingold and Leifeld, 2014). It provides a meso-level view inside policy processes, which traditional climate policy integration studies often lack. Indeed, central actors in a policy network are powerful actors, with the capacity to influence the attitudes and behaviour of other actors (Knoke, 1994). Our results show that, despite the predominance of certain actors and homophily in some groups, there is potential for multi-actor coordination and cooperation in the climate change policy network of Peru. Our analysis sheds new light on the internal aspects of climate policy integration, mainly on the integration of $A \& M$ subdomains, which is key to effective climate action, notably in the land-use sectors (Di Gregorio et al., 2017). We also showed that information exchanges and collaborative ties, while correlated, serve different purposes (Carpenter et al., 2004) and indeed display distinct structural, dyadic and relational characteristics differing by type of actors and policy sub-domain. Importantly, our results provide evidence of: (i) concentration of power in national government, particularly in the mitigation subdomain, and isolation of groups that matter for policy implementation; (ii) slight predominance of mitigation over adaptation; and (ii) the existence of actors in good positions for brokering relationships between the subdomains. We discuss these three points in relation to our initial propositions.

\section{Concentration of power in national government}

The concentration of power in national government reflects the specific structural role state actors hold in society, as they can make binding policy decisions. It also reflects national ownership over climate change policy processes in both subdomains, confirming proposition P1. Even though international organizations were the second most central group in most layers (confirming proposition $\mathrm{P} 2$ ), national government organizations have retained the key steering power in both A\&M.

The power of national government organizations leaves them with a special responsibility in terms of coordinating learning and action to enable collective sense-making (Bodin and Prell, 2011). In the specific case of Peru, the Ministry of Environment has the direct jurisdiction, in theory, over all activities related to climate change, which it oversees through its different General Directorates. The Ministry of Agriculture (and its different directorates) has key powers and responsibilities related to forests and land use. These national government organizations make policy binding decisions and are, by design, central in the network, despite decentralization efforts in Peru.

Despite the centrality of national government actors, diverse non-state actors had central roles in the network and national civil society actors were relatively central in both A\&M exchanges. This suggests that the climate change policy domain of Peru presents features of polycentric and monocentric systems at the same time, which confirms previous observations that these two types of governance systems almost always coexist and that the dichotomy between polycentric and monocentric governance is too simplistic (Galaz et al., 2012; Morrison et al., 2019).

Understanding $A \& M$ in polycentric systems requires not only to analyse the structures of the decentralized networks, but also to examine the configuration of power relations across these structures. However contradictory as it might seem, polycentrism is itself embedded in hierarchical or multilevel power dynamics that can move the system across decentralized, recentralized and fragmented states (Morrison et al., 2017). Thus, the analysis and practice of climate change governance, and particularly the aspirations towards climate policy integration, need to be more explicit about these dynamics in order to reveal and address imbalances, and strive for better outcomes. 
Our analysis showed that private sector organizations in Peru were isolated with regards to information sharing and collaboration. This may be explained by the fact that many businesses are not engaged in climate change action and are not interested enough in climate change issues to put time and effort into engaging with other policy actors. This is a concern, as those actors should play a role in reducing emissions and facilitating adaptive actions.

In our analysis, subnational government actors did not fare well in information sharing in the national domain with other actors in Peru or subnational NGOs in all kinds of interactions. From the perspective of polycentric governance, local sites need to be connected to actors at the higher level, who in turn need to understand local experiences and guide local experimentation (Morrison et al., 2017). Subnational and non-state actors have a direct impact on the success of climate policy integration and governance, but their indirect impacts can also be big, such as those stemming from innovation, experimentation, demonstration of best practices and capacity building (Chan et al., 2015).

Explaining the isolation of certain actor groups is not straightforward. Private sector actors ranked the lowest in terms of indegrees, either because they believe they are not very affected by climate policy developments and thus feel no need to be involved or because they operate behind the scenes (Falkner, 2017; Guzzini, 1993). Other non-state actors may have more interest in connecting to the policy domain. Building communication links with those actors, who have a role to play in reducing emissions and vulnerability is important from the beginning of the policy process. Polycentric governance research has shown that levels of communication affect trust levels, which in turn substantially determine cooperation levels (Cole, 2015). Actors who only interact within their groups develop their own subcultures and reject collective action within a wider group (Bodin, 2017).

\section{Predominance of mitigation over adaptation}

Similar to evidence from Brazil and Indonesia (Di Gregorio et al., 2019), our results show that the mitigation policy subdomain is dominant in the climate change policy network of Peru, confirming our proposition $\mathrm{P} 3$. This is not only indicated by the higher densities of the mitigation ties as compared to adaptation, but also by the higher indegrees of the most central actors, which could mean that there are stronger influencers in the mitigation subdomain.

In the case of Peru, the attention given to mitigation can be related to the large areas of tropical Amazon forests, which play an important role in the global carbon cycle. Most national climate change policies at the time of our research had mitigation at their core, such as the National Forest and Climate Change Strategy and the National Forest Conservation Program, as shown by a policy document analysis (Pramova et al., 2015). Forest-based mitigation had also attracted a considerable amount of foreign funding streams such as those coming from Germany, Norway, and the World Bank. In contrast, adaptation activities seemed to be more dispersed and less visible in national policy networks.

Further evidence of the dominance of mitigation over adaptation is that actors with higher reputational power in the mitigation subdomain exchange more information and collaborate more in both $A \& M$ subdomains (challenging our proposition $\mathrm{P} 6$ ), while actors with higher reputational power in adaptation are more active in adaptation but not in mitigation (confirming P6). This suggests that the central actors in mitigation can be agents of change for internal climate policy integration, as reputation matters (Ingold and Leifeld, 2014). However, it is unclear whether these central actors in mitigation have an interest in considering adaptation. Another possible interpretation of our result could be that central actors in adaptation are not recognized in the mitigation subdomain because mitigation actors are not really interested in adaptation.

Adaptation is indeed the newer policy subdomain (Anguelovski and Carmin, 2011). Most governments have had more practical experience in emissions reduction and the policy fixes required for mitigation are generally better understood, while adaptation remains ambiguous (Doelle 
et al., 2012; Hall, 2017). Furthermore, the mitigation subdomain is characterized by exogenous drivers of action stemming from global pressures to curb climate change (Anguelovski and Carmin, 2011), which has resulted in mitigation having historically attracted a major share of global climate finance (Pickering et al., 2015).

We did not find evidence to confirm proposition P4 on the inclination of international actors toward mitigation and of subnational actors toward adaptation in the national-level policy network: central actors from subnational governments ranked similarly in A\&M, whereas international NGOs and foreign agencies ranked high in adaptation, probably because of the relevance of adaptation to development programs. Regarding proposition P5 on different sectoral engagement in A\&M, we only found evidence of higher engagement of the forestry sector in mitigation, which is easily explained by REDD+ policy discussions in Peru. That different levels and sectors are interested in both A\&M is a good sign for climate policy integration.

\section{Homophily and brokers}

Whereas the private sector, research organizations and NGOs (to some extent) exhibited homophily, government actors and international actors did not. Thus, our proposition P7 can be only partially confirmed. The fact that the most dominant actor groups did not exhibit homophily is good news for multi-actor communication and coordination, in contrast to evidence from Brazil and Indonesia, where some level of homophily was found within all types, except for the private sector (Di Gregorio et al., 2019).

The absence of homophily among national government organizations can also be related to the fact that the interviews were conducted after COP20 in Lima, which required national government organizations to share information and collaborate widely in the country. We hypothesize that the organization of such a major international event by a government modifies strongly the structure of the climate change policy network, although we were not able to compare the network before and after.

The homophily exhibited by private sector, research organizations and NGOs could be problematic for successful policy development and implementation, but some homophily is to be expected and might be healthy at least for some actors. Previous studies showed that for interest groups who lobby government (this would include NGOs as well as the business sector), a degree of homophily is to be expected in information exchanges (Leifeld and Schneider, 2012), because lobbying activities require a lot of information sharing. For research organizations, we might expect less homophily in information networks, if we want them to disseminate information to non-research actors. Also, homophily in collaboration ties might mean something different from homophily in information ties. There is a general need to improve communication and engagement across climate science, policy and practice, as decision makers may not use or even receive relevant scientific information (Vogel et al., 2007).

Despite the observed homophily, we found many organizations from different groups to be well positioned to broker integration between the two subdomains. This does not necessarily mean that they were actually engaging in integration: the measure of betweenness centrality across layers only describes brokerage potential from a structural point of view. The actors of importance to potentially bridging $A \& M$ need to actually engage in doing so.

Actors with high indegree centrality and brokerage roles in subdomains are generally well situated to help bridge subdomain boundaries due to their number of ties alone (Bodin, 2017). Indeed, many top inter-layer brokers (mainly national government and international organizations) also exhibited high indegree and brokerage roles in both layers. The top brokers across subdomains were, however, not only organizations with high indegree centrality and brokerage roles in the subdomains, but also several "unusual key players" that were not brokers in any of the two layers separately. On the contrary, some actors with high indegree centrality in both layers and a mandate to work with 
multiple actors and connect organizations ("the usual key players") were surprisingly absent from the top ranks of inter-layer brokers.

These results can be explained by the concept of "structural holes", which describes the nonredundant relationships between actors (Burt, 2009). Some "usual key players" scored low on betweenness centrality because their brokerage role was redundant, i.e. the actors they connected were either directly connected already (redundancy by cohesion) or connected by other organizations (redundancy by structural equivalence). On the other hand, the "unusual key players" occupied a structural hole as they linked pairs of actors via non-redundant ties. This makes "unusual key players" particularly important as potential brokers across $A \& M$, because they are the only potential links between a number of actors across domains.

The "usual key players" might have ended with a low brokerage role across layers as a result of their success in building ties or triggering other actors to form direct ties. Empirical evidence shows that structural holes filled by brokers have a general tendency to close (Quintane et al., 2012). As a result, the advantage that a structural hole provides to a broker will fade out if the broker is successful in helping others connect directly. This brings out important implications for polycentric climate governance and internal climate policy integration: because of the dynamic nature of brokerage, an altruist broker who works to connect people and not to protect its position as a broker will eventually lose its brokerage power. But this broker could also benefit, for example, by exploiting the complementary skills and resources of the newly formed alliances or connected actors (Quintane et al., 2012).

This observation on the dynamic nature of brokerage highlights that our analysis provides a snapshot at a particular point in time of the climate policy network, which can change considerably over time (Morrison, 2017). If redone periodically, a policy network analysis can help understand how structure and power evolve in climate change governance and how this evolution supports climate policy integration. It can also shed light into power dynamics, an issue that is often downplayed in governance analyses (Morrison et al., 2019) and highlight relational power determinants alongside other structural power dimensions (Leifeld and Schneider 2012), which remains a fairly new research direction in the climate change sub-domains of A\&M (Di Gregorio et al., 2019).

\section{Conclusion}

This study examined information flows and collaborations in national climate change policy in Peru through a multiplex network approach distinguishing climate change A\&M policy subdomains. Results showed that national government institutions are central actors in climate change policy networks in Peru, which may reflect national ownership of the climate change issue. Private sector organizations and subnational actors in Peru are the least involved in information sharing and collaboration on climate change. The mitigation policy subdomain is dominant in the climate change policy network of Peru but actors from different levels and sectors are active in both adaptation and mitigation, which is a good sign for climate policy integration. Despite the predominance of certain actors and homophily in some groups, there is good potential for multi-actor coordination and cooperation in the climate change policy network of Peru. Actors with the capacity to bridge the two policy subdomains are not only the central actors in each subdomain but also the actors that close structural holes between subdomains.

Using Peru as a case study, this study has shown that policy network analysis is a relevant approach to assess the level of internal climate policy integration in the land-use sector. This approach could be applied to identify key policy brokers in other countries, where the integration of adaptation and mitigation faces similar challenges related to the institutional complexity created by the diversity of actors involved. An important lesson from this study for other countries is that key actors for climate policy integration are not only the key actors in either adaptation or mitigation (such as national 
government institutions) but also actors that close structural holes between adaptation and mitigation in the climate policy network.

\section{Acknowledgements}

The funding partners that have supported this research include the International Climate Initiative (IKI, project 15_III_075) of the German Federal Ministry for the Environment, Nature Conservation, Building and Nuclear Safety (BMUB), the Norwegian Agency for Development Cooperation (agreement QZA-016/0110), the French funding agency for research (project TRASSE ANR-CONACYT17-CE32-0012), the Economic and Social Research Council (ESRC) (grant number ES/K00879X/1), the Centre for Climate Change Economics and Policy (CCCEP) (ESRC grant number ES/K006576/1), and the CGIAR Research Program on Forests, Trees and Agroforestry (CRP-FTA) with financial support from the CGIAR Fund. The authors thank all interviewees for participating in this study.

\section{References}

Adelle, C., Russel, D. (2013) Climate policy integration: A case of deja vu? Environmental Policy and Governance 23, 1-12.

Anguelovski, I., Carmin, J. (2011) Something borrowed, everything new: innovation and institutionalization in urban climate governance. Current Opinion in Environmental Sustainability 3, 169-175.

Battiston, S., Caldarelli, G., Garas, A. (2018) Multiplex and Multilevel Networks. Oxford University Press, Oxford.

Berardo, R., Scholz, J.T. (2010) Self-organizing policy networks: Risk, partner selection, and cooperation in estuaries. American Journal of Political Science 54, 632-649.

Bodin, Ö. (2017) Collaborative environmental governance: Achieving collective action in socialecological systems. Science 357, eaan1114.

Bodin, Ö., Prell, C., (2011) Social networks and natural resource management: Uncovering the social fabric of environmental governance. Cambridge University Press, Cambridge, UK.

Borgatti, S.P., Mehra, A., Brass, D.J., Labianca, G. (2009) Network analysis in the social sciences. Science 323, 892-895.

Börzel, T.A. (1998) Organizing Babylon-On the different conceptions of policy networks. Public Administration 76, 253-273.

Broadbent, J., Vaughter, P., (2014) Inter-disciplinary analysis of climate change and society: A network approach, in: Manfredo, M.J., Vaske, J.J., Rechkemmer, A., Duke, E.A. (Eds.), Understanding society and natural resources. Springer, Dordrecht, The Netherlands, pp. 203-228.

Brockhaus, M., Di Gregorio, M. (2014) National REDD+ policy networks: from cooperation to conflict. Ecology and Society 19, 14.

Brockhaus, M., Di Gregorio, M., Carmenta, R. (2014) REDD+ policy networks: exploring actors and power structures in an emerging policy domain. Ecology and Society 19, 29.

Bulkeley, H. (2005) Reconfiguring environmental governance: Towards a politics of scales and networks. Political Geography 24, 875-902.

Burt, R.S. (2004) Structural holes and good ideas. American Journal of Sociology 110, 349-399.

Burt, R.S. (2009) Structural holes: The social structure of competition. Harvard university press. 
Butts, C.T., Morris, M., Krivitsky, P.N., Almquist, Z., Handcock, M.S., Hunter, D.R., Goodreau, S.M., deMoll, S.B., (2015) Introduction to Exponential-family Random Graph (ERG or p*) modeling with ergm. CRAN project, http://cran.r-project.org/web/packages/ergm/vignettes/ergm.pdf.

Calliari, E., Michetti, M., Farnia, L., Ramieri, E. (2019) A network approach for moving from planning to implementation in climate change adaptation: Evidence from southern Mexico. Environmental Science \& Policy 93, 146-157.

Carlsson, L. (2000) Policy networks as collective action. Policy Studies Journal 28, 502-520.

Carlsson, L., Sandström, A. (2008) Network governance of the commons. International Journal of the Commons 2, 33-54.

Carpenter, D.P., Esterling, K.M., Lazer, D.M. (2004) Friends, brokers, and transitivity: Who informs whom in Washington politics? The Journal of Politics 66, 224-246.

Cashore, B., Vertinsky, I. (2000) Policy networks and firm behaviours: Governance systems and firm reponses to external demands for sustainable forest management. Policy Sciences 33, 1-30.

Chan, S., van Asselt, H., Hale, T., Abbott, K.W., Beisheim, M., Hoffmann, M., Guy, B., Höhne, N., Hsu, A., Pattberg, P. (2015) Reinvigorating international climate policy: a comprehensive framework for effective nonstate action. Global Policy 6, 466-473.

Chazarin, F., Locatelli, B., Garay-Rodríguez, M. (2014) Mitigación en la selva, adaptación en la sierra y la costa: Oportunidades perdidas de sinergias frente al cambio climático en Perú? Ambiente y Desarrollo 18, 95-107.

Cole, D.H. (2015) Advantages of a polycentric approach to climate change policy. Nature Climate Change 5, 114.

Cranmer, S.J., Desmarais, B.A. (2011) Inferential network analysis with exponential random graph models. Political Analysis 19, 66-86.

Csardi, G., (2018) igraph: Routines for simple graphs and network analysis, version 1.2.2.

https://cran.r-project.org/package=igraph.

De Domenico, M., Solé-Ribalta, A., Omodei, E., Gómez, S., Arenas, A. (2015) Ranking in interconnected multilayer networks reveals versatile nodes. Nature Communications 6, 6868.

den Hertog, L., Stross, S. (2013) Coherence in EU external relations: Concepts and legal rooting of an ambiguous term. European Foreign Affairs Review 18, 373-388.

Di Gregorio, M., Fatorelli, L., Paavola, J., Locatelli, B., Pramova, E., Nurrochmat, D.R., May, P.H., Brockhaus, M., Sari, I.M., Kusumadewi, S.D. (2019) Multi-level governance and power in climate change policy networks. Global Environmental Change 54, 64-77.

Di Gregorio, M., Nurrochmat, D.R., Paavola, J., Sari, I.M., Fatorelli, L., Pramova, E., Locatelli, B., Brockhaus, M., Kusumadewi, S.D. (2017) Climate policy integration in the land use sector: Mitigation, adaptation and sustainable development linkages. Environmental Science \& Policy 67, 35-43.

Dickison, M.E., Magnani, M., Rossi, L. (2016) Multilayer social networks. Cambridge University Press, New York.

Doelle, M., Henschel, C., Smith, J., Tollefson, C., Wellstead, A. (2012) New governance arrangements at the intersection of climate change and forest policy: institutional, political and regulatory dimensions. Public Administration 90, 37-55.

Falkner, R. (2017) Business power and conflict in international environmental politics. Springer, New York. 
Fischer, M., Sciarini, P. (2015) Unpacking reputational power: Intended and unintended determinants of the assessment of actors' power. Social Networks 42, 60-71.

Galaz, V., Crona, B., Österblom, H., Olsson, P., Folke, C. (2012) Polycentric systems and interacting planetary boundaries-Emerging governance of climate change-ocean acidification-marine biodiversity. Ecological Economics 81, 21-32.

Gallemore, C., Di Gregorio, M., Moeliono, M., Brockhaus, M. (2015) Transaction costs, power, and multi-level forest governance in Indonesia. Ecological Economics 114, 168-179.

Gargiulo, M., Benassi, M. (2000) Trapped in your own net? Network cohesion, structural holes, and the adaptation of social capital. Organization Science 11, 183-196.

Gebara, M.F., Fatorelli, L., May, P., Zhang, S. (2014) REDD+ policy networks in Brazil: constraints and opportunities for successful policy making. Ecology and Society 19, 53.

Ghariblou, S., Salehi, M., Magnani, M., Jalili, M. (2017) Shortest paths in multiplex networks. Scientific Reports 7, 2142.

Granovetter, M.S., (1977) The strength of weak ties, in: Leinhardt, S. (Ed.), Social networks: a developing paradigm. Academic Press, New York, pp. 347-367.

Guzzini, S. (1993) Structural power: the limits of neorealist power analysis. International Organization 47, 443-478.

Hall, N. (2017) What is adaptation to climate change? Epistemic ambiguity in the climate finance system. International Environmental Agreements: Politics, Law and Economics 17, 37-53.

Handcock, M.S., Hunter, D.R., Butts, C.T., Goodreau, S.M., Krivitsky, P.N., Bender-deMoll, S., Morris, M., (2016) Package 'statnet': Software Tools for the Statistical Analysis of Network Data, version 2016.9, https://cran.r-project.org/package=statnet.

Heaney, M.T. (2014) Multiplex networks and interest group influence reputation: An exponential random graph model. Social Networks 36, 66-81.

Ingold, K. (2011) Network structures within policy processes: Coalitions, power, and brokerage in Swiss climate policy. Policy Studies Journal 39, 435-459.

Ingold, K. (2017) How to create and preserve social capital in climate adaptation policies: A network approach. Ecological Economics 131, 414-424.

Ingold, K., Leifeld, P. (2014) Structural and institutional determinants of influence reputation: A comparison of collaborative and adversarial policy networks in decision making and implementation. Journal of Public Administration Research and Theory 26, 1-18.

Kivelä, M., Arenas, A., Barthelemy, M., Gleeson, J.P., Moreno, Y., Porter, M.A. (2014) Multilayer networks. Journal of complex networks 2, 203-271.

Knoke, D. (1993) Networks of elite structure and decision making. Sociological methods \& research 22, 23-45.

Knoke, D. (1994) Political networks: the structural perspective. Cambridge University Press.

Knoke, D., Pappi, F.U., Broadbent, J., Tsujinaka, Y. (1996) Comparing policy networks: labor politics in the US, Germany, and Japan. Cambridge University Press, Cambridge.

Knoke, D., Yang, S. (2008) Social network analysis. Sage, Thousand Oaks, CA.

Kongsager, R., Locatelli, B., Chazarin, F. (2016) Addressing climate change mitigation and adaptation together: A global assessment of agriculture and forestry projects. Climatic Change,

doi:10.1007/s00267-00015-00605-y. 
Koskinen, J., Daraganova, G., (2013) Exponential Random Graph Model Fundamentals, in: Lusher, D., Robins, G., Koskinen, J. (Eds.), Exponential Random Graph Models for Social Networks: Theory, Methods, and Applications. Cambridge University Press, Cambridge, pp. 49-76.

Kriesi, H., Jegen, M. (2001) The Swiss energy policy elite: The actor constellation of a policy domain in transition. European journal of political research 39, 251-287.

Kumar, T., Narayanan, M., Ravindran, B. (2019) Effect of Inter-layer Coupling on Multilayer Network Centrality Measures. Journal of the Indian Institute of Science 99, 237-246.

Laumann, E.O., Knoke, D. (1987) The organizational state: Social choice in national policy domains. Univ of Wisconsin Press, Madison, WI.

Lee, T. (2019) Network comparison of socialization, learning and collaboration in the C40 cities climate group. Journal of Environmental Policy \& Planning 21, 104-115.

Lee, Y., Lee, I.W., Feiock, R.C. (2012) Interorganizational collaboration networks in economic development policy: An exponential random graph model analysis. Policy Studies Journal 40, 547573.

Leifeld, P., Schneider, V. (2012) Information exchange in policy networks. American Journal of Political Science 56, 731-744.

Locatelli, B., (2011) Synergies between adaptation and mitigation in a nutshell. Center for International Forestry Research, Bogor, Indonesia. doi:10.17528/cifor/003619.

Locatelli, B., Catterall, C.P., Imbach, P., Kumar, C., Lasco, R., Marín-Spiotta, E., Mercer, B., Powers, J.S., Schwartz, N., Uriarte, M. (2015a) Tropical reforestation and climate change: beyond carbon. Restoration Ecology 23, 337-343.

Locatelli, B., Evans, V., Wardell, A., Andrade, A., Vignola, R. (2011) Forests and Climate Change in Latin America: Linking Adaptation and Mitigation. Forests 2, 431-450.

Locatelli, B., Fedele, G., Fayolle, V., Baglee, A. (2016) Synergies between adaptation and mitigation in climate change finance. International Journal of Climate Change Strategies and Management 8, 112128.

Locatelli, B., Pavageau, C., Pramova, E., Di Gregorio, M. (2015b) Integrating climate change mitigation and adaptation in agriculture and forestry: opportunities and trade-offs. Wiley Interdisciplinary Reviews: Climate Change 6, 585-598.

Lubell, M. (2007) Familiarity breeds trust: Collective action in a policy domain. The Journal of Politics 69, 237-250.

Lusher, D., Robins, G., (2013) Formation of Social Network Structure, in: Lusher, D., Robins, G., Koskinen, J. (Eds.), Exponential Random Graph Models for Social Networks: Theory, Methods, and Applications. Cambridge University Press, Cambridge, pp. 16-28.

Marsh, D., Rhodes, R.A.W. (1992) Policy networks in British government. Clarendon Press, Oxford.

Marsh, D., Smith, M. (2000) Understanding policy networks: towards a dialectical approach. Political studies 48, 4-21.

McAllister, R.R., McCrea, R., Lubell, M.N. (2014) Policy networks, stakeholder interactions and climate adaptation in the region of South East Queensland, Australia. Regional Environmental Change 14, 527-539.

McPherson, M., Smith-Lovin, L., Cook, J.M. (2001) Birds of a feather: Homophily in social networks. Annual review of sociology 27, 415-444. 
Menton, M., Perla, J., Sotes, J., Fatorelli, L. (2014) Analysis of REDD+ policy networks in Peru. Center for International Forestry Research (CIFOR) Occasional Paper no. 106, doi:10.17528/cifor/004438, Bogor, Indonesia.

Morrison, T.H. (2017) Evolving polycentric governance of the Great Barrier Reef. Proceedings of the National Academy of Sciences 114, E3013-E3021.

Morrison, T.H., Adger, W.N., Brown, K., Lemos, M.C., Huitema, D., Hughes, T.P. (2017) Mitigation and adaptation in polycentric systems: sources of power in the pursuit of collective goals. Wiley Interdisciplinary Reviews: Climate Change 8, e479.

Morrison, T.H., Adger, W.N., Brown, K., Lemos, M.C., Huitema, D., Phelps, J., Evans, L., Cohen, P., Song, A.M., Turner, R., Quinn, T., Hughes, T.P. (2019) The black box of power in polycentric environmental governance. Global Environmental Change 57, 101934.

Nilsson, M., Zamparutti, T., Petersen, J.E., Nykvist, B., Rudberg, P., McGuinn, J. (2012) Understanding policy coherence: analytical framework and examples of sector-environment policy interactions in the EU. Environmental Policy and Governance 22, 395-423.

Oberlack, C. (2017) Diagnosing institutional barriers and opportunities for adaptation to climate change. Mitigation and Adaptation Strategies for Global Change 22, 805-838.

Oliver-Smith, A., (2014) Climate change adaptation and disaster risk reduction in Highland Peru, in: Glavovic, B.C., Smith, G.P. (Eds.), Adapting to Climate Change: Lessons from Natural Hazards Planning. Springer, Dordrecht, Netherlands, pp. 77-99.

Persson, Å., (2013) Different perspectives on EPI, in: Eckerberg, K., Nilsson, M. (Eds.), Environmental Policy Integration in Practice: Shaping Institutions for Learning. Routledge, London, pp. 45-68.

Pham, T.T., Moeliono, M., Locatelli, B., Brockhaus, M., Di Gregorio, M., Mardiah, S. (2014) Integration of Adaptation and Mitigation in Climate Change and Forest Policies in Indonesia and Vietnam. Forests 5, 2016-2036.

Pickering, J., Skovgaard, J., Kim, S., Roberts, J.T., Rossati, D., Stadelmann, M., Reich, H. (2015) Acting on climate finance pledges: Inter-agency dynamics and relationships with aid in contributor states. World Development 68, 149-162.

Pielke Jr, R., Prins, G., Rayner, S., Sarewitz, D. (2007) Lifting the taboo on adaptation. Nature 445, 597-598.

Piu, H.C., Menton, M. (2014) The context of REDD+ in Peru: Drivers, agents and institutions. CIFOR Occasional Paper no. 106, doi:10.17528/cifor/004438, Bogor, Indonesia.

Pramova, E., Di Gregorio, M., Locatelli, B., (2015) Integrating adaptation and mitigation in climate change and land-use policies in Peru. CIFOR, Bogor, Indonesia.

Quintane, E., Carnabuci, G., Robins, G.L., Pattison, P.E. (2012) How do brokers broker? An investigation of the temporality of structural holes. Academy of Management Proceedings 1, 11234.

R Core Team, (2018) R: A language and environment for statistical computing. R version 3.5.1 (201807-02). R Foundation for Statistical Computing, Vienna, Austria, https://www.r-project.org/.

Robins, G., Lusher, D., (2013) What Are Exponential Random Graph Models?, in: Lusher, D., Robins, G., Koskinen, J. (Eds.), Exponential Random Graph Models for Social Networks: Theory, Methods, and Applications. Cambridge University Press, Cambridge, pp. 9-15.

Russel, D., Turnpenny, J., Jordan, A. (2018) Mainstreaming the environment through appraisal: Integrative governance or logics of disintegration? Environment and Planning C: Politics and Space $36,1355-1370$. 
Schmidt, N.M., Fleig, A. (2018) Global patterns of national climate policies: Analyzing 171 country portfolios on climate policy integration. Environmental Science \& Policy 84, 177-185.

Scobie, M. (2016) Policy coherence in climate governance in Caribbean small island developing states. Environmental Science \& Policy 58, 16-28.

Shrestha, S., Dhakal, S. (2019) An assessment of potential synergies and trade-offs between climate mitigation and adaptation policies of Nepal. Journal of Environmental Management 235, 535-545.

Smith, P., Calvin, K., Nkem, J., Campbell, D., Cherubini, F., Grassi, G., Korotkov, V., Le Hoang, A., Lwasa, S., McElwee, P., Nkonya, E., Saigusa, N., Soussana, J.-F., Taboada, M.A., Manning, F., Nampanzira, D., Arias-Navarro, C., Vizzarri, M., House, J., Roe, S., Cowie, A., Rounsevell, M., Arneth, A. (2019) Which practices co-deliver food security, climate change mitigation and adaptation, and combat land-degradation and desertification? Global Change Biology, doi:10.1111/gcb.14878.

Solé-Ribalta, A., De Domenico, M., Gómez, S., Arenas, A., (2014) Centrality rankings in multiplex networks, Proceedings of the 2014 ACM conference on Web science. ACM, pp. 149-155.

Stringer, L.C., Dougill, A.J., Thomas, A.D., Spracklen, D.V., Chesterman, S., Speranza, C.I., Rueff, H., Riddell, M., Williams, M., Beedy, T., Abson, D.J., Klintenberg, P., Syampungani, S., Powell, P., Palmer, A.R., Seely, M.K., Mkwambisi, D.D., Falcao, M., Sitoe, A., Ross, S., Kopolo, G. (2012) Challenges and opportunities in linking carbon sequestration, livelihoods and ecosystem service provision in drylands. Environmental Science and Policy 19-20, 121-135.

Swart, R., Raes, F. (2007) Making integration of adaptation and mitigation work: mainstreaming into sustainable development policies? Climate Policy 7, 288-303.

Tosun, J., Lang, A. (2017) Policy integration: mapping the different concepts. Policy Studies 38, 553570.

UNFCCC, (2017) Decision 4/CP.23 Koronivia joint work on agriculture. United Nation Framework Convention on Climate Change, Bonn, Germany.

Vignola, R., McDaniels, T.L., Scholz, R.W. (2013) Governance structures for ecosystem-based adaptation: Using policy-network analysis to identify key organizations for bridging information across scales and policy areas. Environmental Science \& Policy 31, 71-84.

Vogel, C., Moser, S.C., Kasperson, R.E., Dabelko, G.D. (2007) Linking vulnerability, adaptation, and resilience science to practice: Pathways, players, and partnerships. Global Environmental Change 17, 349-364.

Wasserman, S., Faust, K. (1994) Social network analysis: Methods and applications. Cambridge university press, Cambridge.

Weible, C.M., Sabatier, P.A. (2005) Comparing policy networks: Marine protected areas in California. Policy Studies Journal 33, 181-201.

Yun, S.-J., Ku, D., Han, J.-Y. (2014) Climate policy networks in South Korea: alliances and conflicts. Climate Policy 14, 283-301.

Zeng, A., Battiston, S. (2016) The Multiplex Network of EU Lobby Organizations. PLoS ONE 11, e0158062. 